\title{
Neuropsychological and Neurological Deficits in Obsessive-Compulsive Disorder: The Role of Comorbid Depression
}

\author{
Habibollah Ghassemzadeh $^{1 *}$, Ramin Mojtabai $^{2}$, Nargess Karamghadiri ${ }^{1}$, Maryam Noroozian ${ }^{1}$, \\ Vandad Sharifi ${ }^{1}$, Nargess Ebrahimkhani ${ }^{1}$ \\ ${ }^{1}$ Roozbeh Hospital, Department of Psychiatry, School of Medicine, Tehran University of Medical Sciences, Tehran, Iran; ${ }^{2}$ Depart- \\ ment of Mental Health, Johns Hopkins Bloomberg School of Public Health, Baltimore, USA. \\ Email: *hghassemzadeh@tums.ac.ir
}

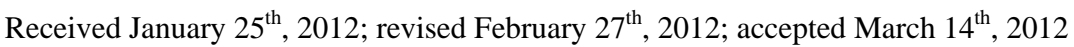

\begin{abstract}
Past research has found a high prevalence of neuropsychological deficits and neurological soft signs in patients with obsessive-compulsive disorder (OCD). A close relationship between OCD and depression has also been indicated in the literature. However, many aspects of this association remain unclear. In this study we compared neuropsychological functioning and neurological soft signs of 46 OCD patients who were off psychotropic medication (21 with significant depressive symptoms and 25 without) with 25 non-patient comparison subjects. The patients were matched to the comparison group with regard to age, sex, education, marital status and handedness. There were significant differences between OCD patients and the non-patient comparison group on neuropsychological functioning but not on neurological soft signs. As far as working memory concerns there was a significant difference between the OCD depressed and nondepressed groups. But we found no evidence that the neuropsychological functions such as cognitive flexibility, problem solving and spatial perception in OCD to be attributable to comorbid depression. The pattern of neuropsychological deficits in this sample of OCD patients is suggestive of orbito-frontal as well as dorso-lateral prefrontal cortical dysfunction.
\end{abstract}

Keywords: Obsessive Compulsive Disorder; OCD; Depression; Neuropsychological Assessment; Neurological Assessment; Soft Signs

\section{Introduction}

Obsessive-compulsive disorder (OCD) is a disabling condition characterized by recurrent intrusive thoughts (obsessions) or impulsive, and repetitive, irresistible and often ritualized behaviors (compulsions), which serve to prevent anxiety and distress or to neutralize the obsessions [1,2]. There has been a growing interest in the organic basis of OCD [3]. Neuroimaging and neurosurgical studies of OCD point to abnormalities in cortical-striatal-thalamic circuits. Specifically, orbito-frontal and anterior cingulate regions have been implicated in this disorder [4-9]. Harkening back to these findings, Savage [10] proposed that neuropsychological impairment in OCD be regarded as an intermediate phenomenon linking brain dysfunctions with clinical symptomatology. In this paradigm, the fronto-striatal dysfunction causes impairment in executive functions. Past studies of executive functions in adults with OCD have identified difficulties in

\footnotetext{
*Corresponding author.
}

planning and organization, inflexibility, and impaired response inhibition [11-16]. The inhibitory failures in OCD patients are consistent with lateral orbito-frontal dysfunction. Set-shifting is classically regarded as a distinct cognitive function based on inhibition, which have been attributed to dorso-lateral prefrontal cortex. As has been indicated in the literature orbito-frontal cortex is more important in response inhibition whereas dorsolateral prefrontal cortex plays an important role in set shifting [17].

The results of the studies investigating neurological deficits in patients with OCD have similarly shown great variability. Schilder [18] reported subtle neurological abnormalities in only about one-third of OCD patients. Similar subtle or "soft" neurological signs were reported in subgroups of patients by Conde et al., [19] and Hollander et al., [20]. These include abnormalities in fine motor coordination, voluntary and mirror movements, and visual and spatial dysfunction. Increased neurological soft signs were associated with greater symptom se- 
verity, increased ventricular size and visual spatial dysfunction. Soft signs also correlated positively with impairment of visual memory and negatively with a measure of set-switching. Although soft signs are non-localizing abnormalities, choreiform movements are consistent with basal ganglia dysfunction and spatial deficits are consistent with right-hemispheric dysfunction $[19,20]$.

A complicating factor in delineation of the specific neuropsychological and neurological deficits of OCD is the high prevalence of comorbid psychiatric conditions often associated with significant deficits, in particular depression. Recent comorbidity studies indicate that as many as $75 \%$ of adults [21] and 52\% of children [22] with OCD have a history of major depressive episodes [23]. These figures have led some to suggest that OCD be regarded a variant of affective illnesses [24]. Furthermore, it has been indicated that depressive symptomatology is associated with executive function, visual organization and other neuropsychological deficits [2529].

There is also some evidence for an association between neurological soft signs in OCD and depression. For example, in one study [30] there was a significant difference between OCD patients with depression and control subjects regarding the presence and type of neurological signs. Several differences ceased to be significant after adjusting for major depressive disorder and the use of major tranquillizers. However, motor sequencing and the "other" sub-scales of the Neurological Evaluation Scale (NES) [31] remained significantly different even after adjusting for depression and medication use. Motor sequencing is dependent on an intact frontal-striatal circuitry and a number of the NES "other" measures (such as gaze impersistence and primitive reflexes) rely on subcortical-frontal integrity [32].

Taken together, the results of these studies raise the possibility that executive function deficits and neurological soft signs found in OCD patients may be attributable in part to comorbid depression. In view of the high prevalence of comorbid depression in OCD, there is a need to further examine the contribution of depression to neuropsychological and neurological deficits of OCD in medication-free patient groups. Moving in this direction not only may help us to develop a new conceptualization of the nature, psychopathology and symptomatology of OCD and/or depression, but new findings may provide us with some criteria useful for diagnosis and treatment.

We report the results of a study comparing the neuropsychological and neurological profiles of a sample of medication-free OCD patients with a non-patient comparison group. Our main question concerns the examination of the role of comorbid depression by comparing the neuropsychological and neurological profiles of subgroups of OCD patients with and without significant de- pressive symptoms.

\section{Method}

\subsection{Participants}

Forty-six Iranian patients meeting the DSM-IV [1] criteria for OCD were included in this study. All patients were off all psychotropic medication for at least 1 month. Patients and control subjects received a standardized clinical interview (semi-structural format for DSM-IV), and completed clinical scales in three different sessions. Exclusion criteria for patients included co-occurring psychiatric disorders, substance abuse, history of a psychotic episode, alcohol dependence, head injury, serious medical conditions or neurological disorder.

\subsection{Assessments}

All diagnoses were confirmed by a clinical psychologist and/or psychiatrist. OCD patients were compared with 25 healthy control subjects matched for gender, handedness, age and education. The Raven Advanced Progressive Matrices [33,34] was used in this study for the purpose of excluding subjects with low IQ (i.e. below than 80) from our samples. Patients were recruited from consecutive referrals to the Psychiatric Clinic of Roozbeh Hospital (a nationally well-known psychiatric and clinical psychology center), Tehran, Iran. Control subjects were recruited through advertising within the hospital (staff and the community) and none was related to the OCD patients. Control subjects were not taking any psychiatric medications and were free of any psychiatric disorder, neurologic disorder, or other significant medical illnesses. Written informed consent was obtained from each subject. Table 1 summarizes the demographic characteristics of the sample. The time frame in which the subjects were recruited and assessed was about six months (starting from July 2009).

Edinburgh Handedness Inventory (EHI) [35] was used to assess handedness. Participants indicated their preference for using the right or left hand for various activities including writing, drawing, striking a match, and opening a box lid. The handedness score is calculated by adding all the scores for the right-hand, subtracting the scores for the left hand, and multiplying by 10. In this study there was not any significant difference between groups in handedness (OCD-depressed group [M = 84.4; $\mathrm{SD}=$ 41.1]; OCD-non-depressed group [M = 88.1; $\mathrm{SD}=29.1]$; and comparison group $[\mathrm{M}=86.4$; $\mathrm{SD}=40.6 ; \mathrm{F}(2,68)=$ $0.06, N S])$.

\subsection{Symptom Measures}

Beck Depression Inventory-Revised (BDI-II) [36] is a measure of severity of depression. Originally introduced 
in 1960s [37], BDI-II was revised to approximate the DSM-IV criteria for major depression [36]. BDI-II was translated into Persian by our group and shown to have excellent internal consistency (Cronbach's alpha $=0.87$ ) and 1 - 2 week test-retest reliability $(r=0.73)$ [38]. BDI-II-Persian contains 21 items, each with a series of four statements describing the severity of depressive symptoms over the past two weeks on a Likert scale from absent to mild $(=0)$ to severe $(=3)$. Total score is computed by summing the item scores (range $=0$ to 63) .

Maudsley Obsessional-Compulsive Inventory (MOCI) is a 30-item true-false questionnaire for assessment of obsessive and compulsive symptoms, developed by Hodgson and Rachman [39]. Maximum scores for the five scales (checking, washing, slowness-repetition, and doubtingconscientious) and total are 9, 11, 7 and 7, 30, respectively. (Some items contribute to more than one subscale; therefore the total score is less than the sum of subscale scores). This inventory was found to have adequate validity and reliability [40] and its Persian translation is widely used [41-43]. Studies on clinical samples have demonstrated good internal consistency for the total MOCI score as well as for the subscales, ranging from 0.60 to 0.87 [44].

Compulsive Activity Checklist (CAC) [45] was originally a 62-item compulsive symptoms inventory describing specific daily activities rated on a 4-point scale of severity. We used a French version of CAC, which is an abbreviated form of the instrument and contains 19 items centered mainly on checking behavior and rituals [46]. The scores range from 0 to 57 . Different versions of CAC have demonstrated good internal consistency, ranging from 0.78 to 0.95 [43]. This test has been translated into Persian and used in our previous studies in Iran [41-43].

\subsection{Neuropsychological Assessments}

Wisconsin Card Sorting Test (WCST) [47] is one of the most widely used tasks to assess the executive function of set shifting. Subjects are asked to sort a deck of cards according to three perceptual categories represented by four "Key" cards. OCD patients have demonstrated deficit in WCST performance in previous studies $[47,12]$. Three performance indexes were scored: categories, total errors, and perseverative errors [48].

Tower of Hanoi (TOH) [49] is the task most commonly applied to assess problem solving and planning ability [50]. TOH is a disk transfer task that requires subjects to work out a sequence of spatially controlled moves in an attempt to reach the state of disk organization. The TOH is generally recognized to be sensitive to frontal lobe dysfunction [51].

The WAIS Block Design Subtest (BD) [52] is a measure of visuospatial and visuoconstructional ability. In past research, OCD subjects have performed worse than control subjects on this subtest [53,54].

Wechsler Memory Scale (WMS) $[55,56]$ is a test of memory comprised of seven subtests: Personal and Current Information, Orientation, Mental Control, Logical Memory, Digits Forward and Backward, Visual Reproduction, and Associate Learning. WMS has been translated into Persian and is commonly used in Iranian samples [56].

\subsection{Neurological Assessments}

Neurological Evaluation Scale (NES) [31] comprises 26 items designed to assess three functional areas: sensory integration, motor coordination, and sequencing of complex motor acts. In addition, short-term memory, frontal release signs, and eye movement abnormalities are included in an "others" category. The total score and scores for each of the four subscales were used in the study as measures of severity of neurological impairment. The inter-rater reliability (intra-class correlation coefficient) for the subscale scores and the total score ranged from 0.63 (for motor coordination) to 0.99 (for sensory integration). The NES items are presented in a fixed order and all but two items are scored on a three-point scale $(0$, no abnormality; 1 , mild but definite impairment; 2, marked impairment). The "suck" and "snout" reflexes are scored 0 or 2 . Total scores are calculated for each of the three domains, the tests in the "other category" and overall functioning.

\subsection{Procedure}

All measures were administrated and scored by trained examiners, blind to group membership. The entire battery (paper and pencil method) was administrated in three sessions each lasting 1 - 2 hours. Each subject first completed the questionnaires and then the neuropsychological tests were administered in a randomized order on the same day. Finally, all subjects were examined for neurological soft signs after 2 or 3 days.

\subsection{Data Analysis}

We divided the OCD patients into the depressed and nondepressed groups, based on their scores on the BDI-II. We used the scores of greater than 20, identified by Beck and colleagues [37] as indicating moderate, severe or very severe depression as the cut-off point for depression in this study, thus excluding mild depression that is common in OCD patients from the depressed group. Differences between the OCD group and the comparison group on demographic characteristics were examined using t-tests for the continuous variable of age and $\chi^{2}$ for the categorical demographic variables. The depressed and non-depressed OCD patient groups were compared with 
each other and the comparison group using analysis of variance (ANOVA) and post-hoc Tukey tests. We further compared the WMS subscales and the NES using the non-parametric Kruskal-Wallis tests. All analyses were conducted in SPSS, version 10. A $p<0.05$ was considered statistically significant.

\section{Results}

The socio-demographic characteristics of the OCD patients and the comparison group are presented in Table $\mathbf{1 .}$ Matching was successful in making the patient and comparison groups similar with regard to sex, age, education, handedness and marital status as there were no statistically significant differences across groups on these characteristics.

Comparing the depressed and non-depressed OCD groups with the comparison group revealed significant differences between the depressed and non-depressed OCD patients on total $[\mathrm{F}(2,68)=55.98]$, washing $[\mathrm{F}$ $(2,68)=23.33]$ and slowness $[\mathrm{F}(2,68)=6.77]$ of $\mathrm{MOCI}$ scale and on CAC scale $[\mathrm{F}(2,68)=33.92]$ (Table 2). OCD patients with significant depressive symptoms (scores greater than 20 in BDI-II) had more severe OCD symptoms than OCD patients without depressive symp- toms (scores less than 20 in BDI-II). There was a significant difference between OCD depressed and nondepressed patients regarding the total score of WMS [(F, $2,68)=15.80, \mathrm{p}<0.001]$. However, there were no statistically significant differences across the two subgroups of OCD patients on the other neuropsychological functions and neurological tests as shown in Table 2.

ANOVA analysis as well as Kruskal-Wallis Test for the subscales of WMS and NES are presented in Tables $\mathbf{3}$ and $\mathbf{4}$.

There was a significant difference $[\mathrm{F}(2,68)=16.8, \mathrm{P}<$ 0.001] between OCD group (WMS-score = 93) in general and the comparison groups (WMS-score = 110). In our further analysis using ANOVA and Kruskal Wallis Test (Tables 3 and $\mathbf{4}$ ) the following results have been obtained: 1) there was not any significant difference between different groups in terms of orientation and visual reproduction; but 2) the means for comparison group on the subscales of mental control (Mean = 7.28; SD = 1.72), logical memory $($ Mean $=10.12 ; \mathrm{SD}=3.00)$, digit forward and backward (Mean $=10.88$; SD = 1.30) and associate learning $($ Mean $=16.52 ; \mathrm{SD}=2.96)$, were higher than OCD- depressed and non-depressed groups; and 3) on the subscales of information $($ Mean $=6.00 ; \mathrm{SD}=0.00)$ and

Table 1. Socio-demographic characteristics of the groups.

\begin{tabular}{|c|c|c|c|c|}
\hline Variables & $\begin{array}{l}\text { Total sample } \\
\quad(\mathrm{n}=71)\end{array}$ & $\begin{array}{l}\text { OCD patients } \\
\quad(\mathrm{n}=46)\end{array}$ & $\begin{array}{l}\text { Controls } \\
(\mathrm{n}=25)\end{array}$ & $\begin{array}{l}\text { Statistical } \\
\text { Tests }\end{array}$ \\
\hline \multicolumn{5}{|l|}{ Sex } \\
\hline Female, N (\%) & $51(72 \%)$ & $34(74 \%)$ & 17 (67\%) & \\
\hline OCD dep. & - & $19(41 \%)$ & - & \\
\hline OCD non-dep. & - & $15(33 \%)$ & - & $\chi^{2}(1)=0.28$ \\
\hline Male, N (\%) & $20(28 \%)$ & $12(26 \%)$ & 8 (33\%) & \\
\hline OCD dep. & - & $5(42 \%)$ & & \\
\hline OCD non-dep. & - & $7(58 \%)$ & & \\
\hline Age, Mean (SD) & $30.13(7.65)$ & $29.00(7.07)$ & $32.20(6.63)$ & $t(69)=1.86$ \\
\hline \multicolumn{5}{|l|}{ Education, N (\%) } \\
\hline 1 - 9 yrs. & $15(21 \%)$ & $11(24 \%)$ & $4(15 \%)$ & $\chi^{2}(2)=3.87$ \\
\hline 9 - 12 yrs. & 35 (49\%) & 25 (54\%) & $10(41 \%)$ & \\
\hline$>12$ yrs. & 21 (29\%) & $10(22 \%)$ & $11(44 \%)$ & \\
\hline \multicolumn{5}{|l|}{ Marital status, N (\%) } \\
\hline Married & 43 (61\%) & 27 (59\%) & $16(67 \%)$ & $\chi^{2}(2)=3.54$ \\
\hline Divorced & $4(6 \%)$ & $4(9 \%)$ & $0(0 \%)$ & \\
\hline Single & 24 (34\%) & $15(20 \%)$ & 9 (33\%) & \\
\hline
\end{tabular}

Note: None of the tests for comparison of groups were statistically significant at $p<0.05$. 
Table 2. Group comparisons of neuropsychological and neurological assessments.

\begin{tabular}{|c|c|c|c|c|c|c|}
\hline Variables & $\begin{array}{l}\text { OCD } \\
\text { overall } \\
\mathrm{n}=46\end{array}$ & $\begin{array}{l}\text { OCD depressed } \\
\text { (Group 1) } \\
n=25\end{array}$ & $\begin{array}{c}\text { OCD non-depressed } \\
\text { (Group 2) } \\
n=21\end{array}$ & $\begin{array}{l}\text { Controls } \\
\text { (Group 3) } \\
n=25\end{array}$ & \multicolumn{2}{|c|}{$\begin{array}{l}\text { ANOVA comparisons of OCD depressed, } \\
\text { non-depressed and control groups }\end{array}$} \\
\hline MOCI & Mean (SD) & Mean (SD) & Mean (SD) & Mean (SD) & $F(2,68)$ & Post-hoc comparisons \\
\hline Total & 14.24 (5.37) & $16.32(5.14)$ & $11.76(4.61)$ & $4.00(2.20)$ & $55.98^{* * *}$ & $1>2>3$ \\
\hline Checking & 4.41 (1.89) & $4.92(2.04)$ & $3.81(1.50)$ & $1.72(1.21)$ & $24.83^{* * *}$ & $1=2>3$ \\
\hline Washing & $4.04(2.72)$ & $4.49(2.80)$ & $2.95(2.22)$ & $0.84(0.99)$ & $23.33^{* * *}$ & $1>2>3$ \\
\hline Slowness & $2.52(1.62)$ & $3.08(1.44)$ & $1.86(1.59)$ & $1.96(0.68)$ & $6.77^{* *}$ & $1>2,2=3,1>3$ \\
\hline Doubts & 4.89 (1.75) & $5.12(1.62)$ & $4.62(1.91)$ & $1.88(1.30)$ & $28.89^{* * *}$ & $1=2>3$ \\
\hline CAC & $16.11(12.73)$ & $22.08(13.01)$ & $9.00(8.00)$ & $1.20(3.07)$ & $33.92^{* * *}$ & $1>2>3$ \\
\hline \multicolumn{7}{|l|}{ WCST } \\
\hline Perseveration error & 11.15 (8.91) & $12.24(9.25)$ & $9.86(8.53)$ & $3.24(4.44)$ & $9.21^{* * *}$ & $1=2>3$ \\
\hline Total error & $21.26(14.14)$ & 23.04 (13.62) & 19.14 (14.79) & $8.12(6.90)$ & $10.13^{* * *}$ & $1=2,1>3$ \\
\hline Categories & $4.17(2.36)$ & $3.76(2.55)$ & $4.67(2.06)$ & $5.84(.80)$ & $7.20^{* *}$ & $1=2,1>3$ \\
\hline \multicolumn{7}{|l|}{ WAIS } \\
\hline WAIS-Block Design & $25.91(9.01)$ & $24.00(10.20)$ & 28.19 (6.93) & $35.92(5.90)$ & $14.44^{* * *}$ & $1=2>3$ \\
\hline \multicolumn{7}{|l|}{ WMS } \\
\hline WMS-Memory quotient & $92.83(13.30)$ & $89.32(14.26)$ & $97.00(10.46)$ & $109.92(12.38)$ & $16.77^{* * *}$ & $1=2>3$ \\
\hline \multicolumn{7}{|l|}{$\mathrm{TOH}$} \\
\hline Number of movements & $12.71(6.88)$ & $12.20(7.22)$ & $13.33(6.57)$ & $8.52(3.06)$ & $4.37^{*}$ & $1=2,2>3,1=3$ \\
\hline \multicolumn{7}{|l|}{ NES } \\
\hline Total Score & $3.7(4.2)$ & $4.4(4.9)$ & $2.5(3.4)$ & $3.7(4.0)$ & 1.09 & $1=2=3$ \\
\hline $\begin{array}{l}\text { Sensory integrative } \\
\text { Subscale }\end{array}$ & $1.0(0.7)$ & $1.3(0.9)$ & $0.6(0.3)$ & $1.1(0.8)$ & 2.18 & $1=2=3$ \\
\hline $\begin{array}{l}\text { Motor coordination } \\
\text { Subscale }\end{array}$ & $0.6(0.3)$ & $0.7(0.4)$ & $0.4(0.2)$ & $0.4(0.1)$ & 1.21 & $1=2=3$ \\
\hline $\begin{array}{l}\text { Sequencing of complex } \\
\text { motor acts subscale }\end{array}$ & $1.5(1.2)$ & $1.7(1.5)$ & $1.0(0.9)$ & $1.4(1.2)$ & 0.89 & $1=2=3$ \\
\hline Other subscales & $2.0(2.0)$ & $2.2(2.2)$ & $1.0(0.9)$ & $1.8(1.8)$ & 0.22 & $1=2=3$ \\
\hline
\end{tabular}

${ }^{*} p<0.05 ;{ }^{* *} p<0.01 ;{ }^{* * *} p<0.001$.

Table 3. ANOVA of WMS subscales \& total score.

\begin{tabular}{lcc}
\hline \multicolumn{1}{c}{ Subscales } & $\mathrm{F}(2,68)$ & Post-hoc comparisons $^{\mathrm{a}}$ \\
\hline Current information & $12.09^{*}$ & $1<2<3$ \\
Orientation & 0.00 & - \\
Mental control & $6.96^{*}$ & $1=2<3$ \\
Logical memory & $6.66^{*}$ & $1=2<3$ \\
Digit span & $15.48^{*}$ & $1=2<3$ \\
Visual reproduction & 0.57 & - \\
Associate learning & $3.11^{*}$ & $1=2<3$ \\
Total score & $15.80^{*}$ & $1<2<3$ \\
\hline
\end{tabular}

a 1 : represents OCD depressed group; 2: OCD non-depressed group and 3: control group; ${ }^{*} p<0.05$. the total score $($ Mean $=102.76$; $\mathrm{SD}=6.59)$ the mean for the control group was higher than OCD non-de- pressed group $($ Mean $=5.76 ; \mathrm{SD}=0.44$ and Mean $=95.55 ; \mathrm{SD}=$ 6.87). The results obtained using Kruskal Wallis Test were mainly consistent with ANOVA results. For example, regarding WMS subscales such as current information $\left(\chi^{2}[1,2]=13.72\right)$, mental control $\left(\chi^{2}[1,2]=8.85\right)$, logical memory $\left(\chi^{2}[1,2]=0.01\right)$, digit span $\left(\chi^{2}[1,2]=\right.$ 25.27), associate learning $\left(\chi^{2}[1,2]=5.94\right)$ and total score $\left(\chi^{2}[1,2]=19.85\right)$, there were significant differences between three groups.

\section{Discussion}

Integrating the neurological, cognitive and clinical findings, we propose that OCD may be recognized in terms 
of orbitofrontal loop dysfunction and those failures in cognitive and behavioral inhibitory processes appear to be under many of the symptoms and neurocognitive findings.

\subsection{Neuropsychology}

In this sample of Iranian OCD patients, we found significant neuropsychological deficits compared to a matched non-patient comparison group. The differences between OCD patients and the comparison group on set shifting abilities (measured by WCST), problem solving and planning abilities (measured by TOH), visuospatial abilities (measured by Block Design), and memory (measured by WMS) were statistically significant.

Deficit in cognitive flexibility in OCD has long been recognized [57]. Evans et al., [58] have argued that setshifting and flexibility not only require the ability of the individual to attend to a new or different stimulus dimension, but also to inhibit responding to the previously acquired rules. Patients with focal lesions to the orbito- frontal cortex are impaired on probabilistic behavioral tasks, which use the same cognitive abilities as the behavioral reversals needed on some of the inhibitory setshifting tasks [59]. Therefore, inhibitory failures arising from dysfunction in the orbito-frontal cortex are likely to be important in mediating the set-shifting deficits reported in OCD patients [17]. Deficits in the functions such as mental control, cognitive flexibility and abstraction in OCD patients, have been supported by earlier research $[12,47,60-62]$. All the findings agree on the presence of a fronto-cortical dysfunction in OCD. Recent brain imaging studies have documented aberrant hyperactivity of pathways involving the orbito-frontal cortex, the caudate nucleus, and the anterior cingulated cortex in OCD [63]. However, since performance on the WCST seems to be most affected by lesions in the dorso-lateral prefrontal cortex [64,65], it is important to bear in mind that reduction of set shifting impairment to the dysfunction of a single brain region is an over-simplification.

Table 4. Comparison of WMS and NES subscales in OCD subgroups and controls using the Kruskal-Wallis test.

\begin{tabular}{|c|c|c|c|c|c|}
\hline \multirow[b]{2}{*}{ Variables } & \multirow{2}{*}{$\begin{array}{l}\text { OCD depressed } \\
(\mathrm{n}=21) \\
\mathrm{M}(\mathrm{SD})\end{array}$} & \multirow{2}{*}{$\begin{array}{l}\text { OCD non-depressed } \\
(\mathrm{n}=25) \\
\mathrm{M}(\mathrm{SD})\end{array}$} & \multirow{2}{*}{$\begin{array}{l}\text { Controls } \\
(\mathrm{n}=25) \\
\mathrm{M}(\mathrm{SD})\end{array}$} & \multicolumn{2}{|c|}{ Chi- Square $^{a}$} \\
\hline & & & & $\begin{array}{c}\mathrm{I} \\
(\mathrm{df}=1)\end{array}$ & $\begin{array}{c}\mathrm{II} \\
(\mathrm{df}=2)\end{array}$ \\
\hline \multicolumn{6}{|l|}{ Subscales of WMS } \\
\hline Current Information & $5.28(0.79)$ & $5.76(0.44)$ & $6.00(0.00)$ & $13.72^{* * *}$ & $20.29^{* * *}$ \\
\hline Orientation & $5.00(0.29)$ & $5.00(0.00)$ & $5.00(0.00)$ & 0.00 & 0.00 \\
\hline Mental Control & $5.54(1.54)$ & $6.38(1.69)$ & $7.28(1.72)$ & $8.85^{* *}$ & $11.49^{* *}$ \\
\hline Logical Memory & $7.00(0.09)$ & $8.93(3.05)$ & $10.12(3.00)$ & 0.01 & $10.22^{* *}$ \\
\hline Digit For \& Back & $8.62(1.76)$ & $9.05(1.43)$ & $10.88(1.30)$ & $25.27^{* * *}$ & $25.43^{* * *}$ \\
\hline Visual Reproduction & $10.42(3.87)$ & $11.28(2.24)$ & $11.08(2.20)$ & 0.03 & $50.02^{* * *}$ \\
\hline Associate Learning & $14.52(2.65)$ & $15.12(3.11)$ & $16.52(2.96)$ & $5.94^{*}$ & $6.64^{*}$ \\
\hline Total score & $89.92(10.14)$ & 95.55 (6.87) & $102.76(6.59)$ & $19.85^{* * *}$ & $22.16^{* * *}$ \\
\hline \multicolumn{6}{|l|}{ Subscales of NES } \\
\hline Total Score & $4.4(4.9)$ & $2.5(3.4)$ & $3.7(4.0)$ & 0.26 & 0.11 \\
\hline Sensory integrative subscale & $1.3(0.9)$ & $0.6(0.3)$ & $1.1(0.8)$ & -0.62 & 0.08 \\
\hline Motor coordination subscale & $0.7(0.4)$ & $0.4(0.2)$ & $0.4(0.1)$ & 1.49 & 0.28 \\
\hline Sequencing of Complex motor acts subscale & $1.7(1.5)$ & $1.0(0.9)$ & $1.4(1.2)$ & -0.62 & 0.15 \\
\hline Other subscales & $2.2(2.2)$ & $1.0(0.9)$ & $1.8(1.8)$ & 0.50 & 0.13 \\
\hline
\end{tabular}

${ }^{a}$ Two sets of tests were conducted: I. comparing the combined OCD group with the control group, and II. comparing the two depressed and non-depressed OCD groups and the control group; ${ }^{*} p<0.05 ;{ }^{* *} p<0.01 ;{ }^{* * *} p<0.001$. 
We also found a distinction between OCD patients and the non-patient comparison group in problem solving and planning. These deficits suggest a specific motor slowing in OCD patients which may result from deficits of spatial working memory, making it difficult to keep an action plan in memory. Another possibility is that OCD patients' poor performance on such tasks as TOH is secondary to perseverative tendencies which lead to repeating errors before finding the correct solution. Further investigations are needed to elucidate the potential roles of speed and spatial working memory in the performance of OCD patients on tasks assessing planning ability [66].

Visuospatial dysfunction in OCD patients has been found in several studies [45,54]. In our study we found significant differences between the OCD and the nonpatient comparison group in this ability as measured by the Block Design Test. However, it is possible that the observed deficit on this test results from complex interactions between several cognitive functions rather than an elementary visuospatial processing impairment. Although neuropsychological testing has revealed evidence of impairment in visuospatial abilities, non-verbal memory and executive function results of the neuropsychological studies have been inconsistent [29]. This is an important caveat in interpreting past research as many neuropsychological tests involve a combination of several elementary functions and cannot be reduced to a single cognitive function [67].

The possible contribution of memory deficits to OCD psychopathology has received much recent attention [17]. The OCD patients in our study performed worse than the comparison group on most WMS subscales. Evidence from recent studies suggests that memory dysfunction in OCD patients may be partly attributable to an inability to apply efficiently elaborated and organizational cognitive strategies $[68,69]$.

\subsection{The Role of Depression}

Consistent with past research we found that a large proportion of OCD patients were moderately or severely depressed based on BDI-II scores. The OCD patients with comorbid depression had more severe obsessive and compulsive symptoms as measured by MOCI (total, slowness, and washing subscales) and the CAC scale. The means for MOCI total score and the slowness, and washing subscales were different at a statistically significant level between the OCD-depressed and OCD nondepressed groups. However, the differences between these two patient groups were not significant in the case of checking and doubting subscales. Jenike [70] had suggested that OCD checkers may be suffering from pathology that differs in mechanism from other OCD types. Although in our study, checking as a subscale of MOCI could differentiate OCD sample in general from normal sample, there was not any significant difference between OCD depressed and OCD non-depressed in this sub-scale. The same rationale may be true in the case of doubting. As Stein [71] suggests we may assume a range of different kinds of OCD involving different kinds of mechanism. We need, however, more data to explain such a difference between OCD depressed and non-depressed sample.

There was a significant difference between OCD-depressed and OCD-non-depressed patients regarding WMS. However, there were no statistically significant differences across the two subgroups of OCD patients on the other neuropsychological as well as neurological functions.

Regarding the role of depression in neuropsychological aspects of OCD, it is possible that memory biases for threat-related information result from comorbid depression $[72,73]$. That is, because depression is associated with memory biases for negative information [74], OCD patients with comorbid depression may be responsible for overall group differences meaning that memory biases may be largely absent in those with pure OCD. Furthermore, it has been found that executive function deficits among patients with OCD are associated with comorbid depressive symptoms [26-28] and have a negative impact on OCD patients' cognitive functioning [75, 76]. Also, the presence of comorbid depressive symptoms in OCD may deepen the executive dysfunction [28]. Future research needs to determine the degree to which cognitive effects, such as memory biases and executive functions, are unique to OCD versus the result of shared variance with depression.

The lack of significant differences in some neuropsychological measures between two groups of depressed OCD and non depressed OCD patients in our study may be related to our matching mechanism on the one hand and possible different neurocognitive processes in the brain, on the other. Neuropsychological assessments in OCD patients always call for careful attention to the potential impact of comorbid depressive symptoms on cognitive abilities. Similarly, impairment of neurocognitive functioning can be secondary to several neurobiological and neurological parameters. Further investigations using more detailed analyses suggest a positive correlation, namely with a neuropsychological deficits. As such, our findings are at variance with past research which reported an association between depressive symptoms and neuropsychological deficits in OCD patients [26,27], and suggest that these neuropsychological deficits may be genuinely related to the OCD psychopathology. A further complication comes from studies e.g. [77] which propose the notion of increased serotonin transporter functioning being pathogenically involved in OCD and support the explanation of using SSRI's in the treatment of both 
OCD and depression. But extending such results to a neuropsychological domain requires more experimental and clinical work.

Given the structural and functional abnormalities in orbito-frontal cortex and dorso-lateral prefrontal, it is logical to hypothesis that OCD patients would show impaired performance on neurocognitive tasks sub-served by these brain regions. The neuropsychological tests have facilitated the profiling of abnormalities in a diverse array of psychiatric and neurological disorders. Modern cognitive tests allow for hypothesis-driven dissection of different domains of cognition, and can be utilized in patients with focal neurosurgical lesions and in conjunction with brain imaging techniques, facilitating the identification of neural substrates of task performance [17].

In summary, this study found significant neuropsychological deficits in the sample of Iranian OCD patients. One of the strong characteristics of this study is that all of the patients were off medication. These deficits may or may not be attributable to comorbid depression, although patients with comorbid depression presented more severe OCD symptoms. The finding of greater severity of OCD symptomatology in the OCD plus depression group compared to OCD without depression group raises the possibility of confounding due to severity of OCD symptoms. However, the direction of results argues against such confounding as patients with OCD plus depression did not present more severe neuropsychological (except WMS) or neurological deficits compared to patient with OCD without depression. Had severity of OCD symptoms been a confounder of the association of depression and neuropsychological deficits we would have expected to find a greater degree of neuropsychological deficits in the OCD plus depression group compared with the OCD without comorbid depression group.

One of the limitations of the present study was the use of BDI-II scores to separate depressed from non-depressed groups. We chose the scores of greater than 20 on BDI-II as a cut-off point as has been suggested by Blackburn [78] for moderate, severe, and very severe depression. Future research needs to use both structured clinical interview and BDI-II scores in identifying the depressed subgroup. Another limitation is related to the possible relationship between educational level and cognitive abilities. We don't have enough data to support or reject such a possibility. The best way in this regard is to control the educational level of all participants which is not always an easy task in some cultures.

It would be difficult to conclude a specific and straightforward relationship between different areas of the brain and the functions measured by some tests and tasks based on our findings at this stage of work. Substantial evidence has been gathered concerning the biological and cognitive foundations of OCD, but our task is far from complete. Functional neuroimaging has implicated the orbitofrontal cortex, basal ganglia, and thalamus in expression of OCD. Neuropsychological studies have highlighted impairments in cognitive set shifting, hyperactivation of attentional systems, and visuospatial deficits. It can be concluded that a greater emphasis on methodological consistency and as integration of results from neuroimaging and neuropsychological testing will be critical before such account can be possible.

It seems the success of any medical and psychological interventions in the future depends on new findings that will shed light on the very nature of the relation of depression to OCD.

\section{REFERENCES}

[1] American Psychiatric Association, "Diagnostic and Statistical Manual of Mental Disorders," 4th Edition, American Psychiatric Association, Washington DC, 1994.

[2] Ó. F. Goncalves, T. R. Marques, N. F. Lori, A. Sampaio and M. C. Branco, "Obsessive-Compulsive Disorder as a Visual Processing Impairment,” Medical Hypotheses, Vol. 74, No. 1, 2010, pp. 107-109. doi:10.1016/j.mehy.2009.07.048

[3] D. J. Stein, “Obsessive-Compulsive Disorder,” The Lancet, Vol. 360, No. 9330, 2002, pp. 397-405. doi:10.1016/S0140-6736(02)09620-4

[4] L. E. Baxter, "Position Emission Tomography Studies of Cerebral Glucose Metabolism in Obsessive-Compulsive Disorder,” Journal of Clinical Psychiatry, Vol. 55, Suppl. 10, 1994, pp. 54-59.

[5] M. L. Bethier, "Cognitive Function in the Obsessive-Compulsive Disorder Associated with Cerebral Lesions,” Revista de Neurologia, Vol. 30, No. 8, 2000, pp. 762-772.

[6] J. S. Choi, D. H. Kang, J. J. Kim, T. H. Ha, J. M. Lee, T. Youn, et al., "Left Anterior Subregion of Orbito-Frontal Cortex Volume Reduction and Inpaired Organizational Strategies in Obsessive-Compulsive Disorder,” Journal of Psychiatric Research, Vol. 38, No. 2, 2004, pp. 193-199. doi:10.1016/j.jpsychires.2003.08.001

[7] J. S. Kwon, J. J. Kim, J. S. Lee, D. S. Lee, M. S. Kim, et al., "Neural Correlates of Clinical Symptoms and Cognitive Dysfunctions in Obsessive-Compulsive Disorder," Psychiatry Research, Vol. 122, No. 1, 2003, pp. 37-47. doi:10.1016/S0925-4927(02)00104-X

[8] S. L. Rauch, P. J. Whalen, D. Dougherty and M. A. Jenike, "Neurobiological Models of Obsessive-Compulsive Disorder,” In: M. A. Jenike, L. Baer, W. E. Minichello, Eds., Obsessive Compulsive Disorders: Practical Management, Mosby, St. Louis, 1998, pp. 222-253.

[9] S. Saxena, A. Brody, K. M. Maidment, J. J. Dunkin, M. Colgan, S. Aborzian, M. E. Phelphs and L. R. Baxter, "Localized Orbitofrontal and Subcortical Metabolic Changes and Predictors of Response to Paroxetine Treatment in Obsessive-Compulsive Disorder,” Neuropsychopharmacology, Vol. 21, No. 6, 1998, pp. 683-693. doi:10.1016/S0893-133X(99)00082-2 
[10] C. R. Savage, “Neuropsychology of OCD,” In: M. A. Jenike, L. Baer and W. E. Minichello, Eds., Obsessive Compulsive Disorders: Practical Management, Mosby, St. Louis, 1998, pp. 255-275.

[11] B. Cassey, R. Trainor, J. L. Prebdi, A. B. Schubert, L. E. Nystrom, J. N. Giedd, et al., "A Developmental Functional MRI Study of Prefrontal Activation during Performance of a Go-No-Go Task," Journal of Cognitive Neuroscience, Vol. 9, No. 6, 1997, pp. 835-847. doi:10.1162/jocn.1997.9.6.835

[12] J. V. Lucy, C. E. Burness and D. C. Costa, "Wisconsin Card Sorting Task (WCST) and Cerebral Blood Flow in Obsessive-Compulsive Disorder (OCD)," British Journal of Medical Psychology, Vol. 70, No. 4, 1997, pp. 403-411. doi:10.1111/j.2044-8341.1997.tb01916.x

[13] S. V. Muller, S. Johannes, B. Wieringa, A. Weber, K. Muller-Vahl, M. Matzke, H. Kolbe, R. Dengler and T. F. Munte, "Disturbed Monitoring and Response Inhibition in Patients with Gilles de la Tourette Syndrome and CoMorbid Obsessive Compulsive Disorder," Behavioral Neurology, Vol. 14, No. 1-2, 2003, pp. 29-37.

[14] D. R. Rosenberge and M. S. Keshavan, “Toward a Neurodevelopmental Model of Obsessive-Compulsive Disorder,” Biological Psychiatry, Vol. 43, No. 9, 1998, pp. 623640. doi:10.1016/S0006-3223(97)00443-5

[15] K. Rubia, T. Russell, S. Overmeyer, M. J. Brammer, E. T. Bullmore, T. Sharma, et al., "Mapping Motor Inhibition: Conjunctive Brain Activations across Different Versions of Go-No-Go Tasks,” NeuroImage, Vol. 13, No. 2, 2001, pp. 250-261. doi:10.1006/nimg.2000.0685

[16] M. B. Spitznagel and J. A. Suhr, "Executive Function Deficits Associated with Symptoms of Schizotypy and Obsessive-Compulsive Disorder,” Psychiatry Research, Vol. 110, No. 2, 2002, pp. 151-163. doi:10.1016/S0165-1781(02)00099-9

[17] S. R. Chamberlain, A. D. Blackwell, N. A. Fineberg, T. W. Robbins and B. J. Sahakian, "The Neuropsychology of Obsessive Compulsive Disorder: The Importance of Failures in Cognitive and Behavioral Inhibition as Candidate Endophenotypic Markers," Neuroscience and Biobehavioral Reviews, Vol. 29, No. 3, 2005, pp. 399-419. doi:10.1016/j.neubiorev.2004.11.006

[18] P. Schilder, "The Organic Background of Obsessions and Compulsions,” American Journal of Psychiatry, Vol. 94, No. 6, 1993, pp. 1397-1414.

[19] L. V. Conde, M. J. J. de la Gandara, L. M. L. Blanco, R. P. Cerezo, R. M. Martinez and F. A. de Dios, "Minor Neurological Signs in Obsessive-Compulsive Disorders," Acta Luso-Espanolas De Neurologia, Psychiatria Ciencias Afines, Vol. 18, 1990, pp. 143-164.

[20] E. Hollander, C. M. De Caria, J. B. Saud, et al., "Neurological Soft Signs in OCD," Archives General Psychiatry, Vol. 48, No. 3, 1991, pp. 278-279. doi:10.1001/archpsyc.1991.01810270090014

[21] D. Neary, “Classification of the Dementias," Reviews in Clinical Gerontology, Vol. 9, No. 1, 1999, pp. 55-64. doi:10.1017/S0959259899009156

[22] R. Baldwin, S. Jeffries, A. Jackson and C. Sutcliffe, "Neurological Findings in Late Onset Depressive Disorder:
Comparison of Individuals with and without Depression,” The British Journal of Psychiatry, Vol. 186, 2005, pp. 308-313. doi:10.1192/bjp.186.4.308

[23] D. W. Black, R. Noyes, R. B. Goldstein and N. Blum, “A Family Study of Obsessive-Compulsive Disorder," Archives General Psychiatry, Vol. 49, No. 5, 1992, pp. 362368. doi:10.1001/archpsyc.1992.01820050026004

[24] S. E. Swedo and J. L. Rapoport, "Phenomenology and Differential Diagnosis of Obsessive-Compulsive Disorder in Children and Adolescents,” In: J. L., Rapoport, Ed., Obsessive-Compulsive Disorder in Children and Adolescents, American Psychiatric Press, Washington DC, 1989, pp. 13-23.

[25] S. Andrés, T. Boget, L. Lázaro, R. Penadés, A. Morer, Salamero, M. and J. Castro-Fornieles, "Neuropsychological Performance in Children and Adolescents with ObsessiveCompulsive Disorder and Influence of Clinical Variables,” Biological Psychiatry, Vol. 61, No. 8, 2007, pp. 946-951. doi:10.1016/j.biopsych.2006.07.027

[26] A. Aycicegi, W. M. Dinn, C. L. Harris and H. Erkmen, "Neuropsychological Function in Obsessive-Compulsive Disorder: Effects of Comorbid Conditions on Task Performance,” European Psychiatry, Vol. 18, No. 5, 2003, pp. 241-248. doi:10.1016/S0924-9338(03)00065-8

[27] M. R. Basso, R. A. Bornstein, F. C. Carona and R. Morton, "Depression Accounts for Executive Function Deficits in Obsessive-compulsive Disorder,” Neuropsychiatry, Neuropsychology and Behavioral Neurology, Vol. 14, No. 4, 2001, pp. 241-245.

[28] S. Moritz, M. Kloss, H. Jahn, M. Schick and I. Hand, "Impact of Comorbid Depressive Symptoms on Nonverbal Memory and Visuospatial Performance in Obsessive-Compulsive Disorder," Cognitive Neuropsychiatry, Vol. 8, No. 4, 2001, pp. 261-272. doi:10.1080/135468000344000020

[29] J. K. Trivedi, M. Dhyani, D. Goel, S. Sharma, A. P. Singh, P. K. Sinha and R. Tendon, "Neurocognitive Dysfunction in Patients with Obsessive Compulsive Disorder," African Journal of Psychiatry, Vol. 11, No. 3, 2008, pp. 204209.

[30] J. K. Christensen and H. K. Maxwell, "Neuropsychological Performance in Obsessive-Compulsive Disorder,” Biological Psychiatry, Vol. 31, No. 1, 1992, pp. 4-18. doi:10.1016/0006-3223(92)90003-I

[31] R. W. Buchanan and D. W. Heinrichs, "The Neurological Evaluation Scale (NES): A Structured Instrument for the Assessments of Neurological Signs in Schizophrenia," Psychiatry Research, Vol. 27, No. 3, 1989, pp. 335-350. doi:10.1016/0165-1781(89)90148-0

[32] C. M. Zielinski, M. A. Taylor, K. R. Juzwin, "Neuropsychological Deficits in Obsessive-Compulsive Disorder," Neuropsychiatry, Neuropsychology and Behavioral Neurology, Vol. 4, No. 2, 1991, pp. 110-126.

[33] M. N. Barahani, "Raven's Progressive Matrices as Applied to Iranian Children,” Educational \& Psychological Measures, Vol. 34, No. 4, 1974, pp. 443-478.

[34] J. C. Raven, "Progressive Matrices: A Perceptual Test of Intelligence,” Lewis Raven, London, 1938.

[35] R. C. Oldfield, "The Assessment and Analysis of Hand- 
edness: The Edinburgh Inventory,” Neuropsychologia, Vol. 9, No. 1, 1971, pp. 97-113. doi:10.1016/0028-3932(71)90067-4

[36] A. T. Beck, R. A. Steer and G. K. Brown, "Manual for the Beck Depression Inventory-II,” Psychological Corporation, San Antonio, 1996.

[37] A. T. Beck, C. H. Ward, M. Mendelsohn, J .E. Mock and J. K. Erbaugh, “An Inventory for Measuring Depression,” Arch. Gen. Psychiatry, Vol. 4, No. 6, 1961, pp. 561-571. doi:10.1001/archpsyc.1961.01710120031004

[38] H. Ghassemzadeh, R. Mojtabai, N. Karamghadiri and N. Ebrahimkhani, "Psychometric Properties of a PersianLanguage Version of the Beck Depression InventorySecond Edition: BDI-II-Persian,” Depression and Anxiety, Vol. 21, No. 4, 2005, pp. 185-192. doi:10.1002/da.20070

[39] R. Hodgson and S. Rachman, "Obsessive-Compulsive Complaints,” Behaviour Research and Therapy, Vol. 15, No. 5, 1977, pp. 389-395. doi:10.1016/0005-7967(77)90042-0

[40] S. Rachman and R. J. Hodgson, “Obsession and Compulsions,” Prentice-Hall, Englewood Cliffs, 1980.

[41] H. Ghassemzadeh, A. Khamseh and N. Ebrahimkhani, "Symptoms of OCD in a Sample of Iranian Patients," International Journal of Social Psychiatry, Vol. 48, No. 1, 2002, pp. 20-28. doi:10.1177/002076402128783055

[42] H. Ghassemzadeh, J. Bolhari, B. Birashk and M. Salavati, "Responsibility Attitude in a Sample of Iranian Obsessive-Compulsive Patients," International Journal of Social Psychiatry, Vol. 51, No. 1, 2005a, pp. 13-22. doi: $10.1177 / 0020764005053266$

[43] H. Ghassemzadeh, A. Khamseh and N. Ebrahimkhani, “Demographic Variables and Clinical Features of ObsessiveCompulsive Disorder in Iranian Patients (Second Report),” In: B. E. Ling, Ed., Obsessive-Compulsive Disorder Research, Nova Science Publishers, Inc., New York, 2005, pp. 243-271.

[44] T. St. Clare, “Assessment Procedures,” In: R. G. Menzies, ans P. De Silva, Eds., Obsessive-Compulsive Disorder: Theory Research and Treatment, John Wiley, Chrichester, 2003, pp. 239-258.

[45] R. Philpott, "Recent Advances in the Behavioral Measurement of Obsessional Illness, Difficulties to These and Other Instruments,” Scottish Medical Journal, Vol. 20, 1975, pp. 33-40.

[46] J. Cottraux, M. Bouvard, M. Defayolle and P. Messy, "Validity and Factorial Structure of the Compulsive Activity Checklist,” Behavior Therapy, Vol. 19, No. 1, 1988, pp. 45-53. doi:10.1016/S0005-7894(88)80054-6

[47] R. K. Heaton, "Wisconsin Card Sorting Test Manual," Psychological Assessment Resources, Odessa, 1981.

[48] N. Hymas, A. Lees, D. Bolton, K. Epps and D. Head, "The Neurology of Obsessional Slowness,” Brain, Vol. 114, No. 5, 1991, pp. 2203-2233. doi:10.1093/brain/114.5.2203

[49] K. Lezak, "Neuropsychological Assessment,” University Press, Oxford, 1995.

[50] T. Shallice, “Specific Impairments of Planning," Philsophical Transactions of the Royal Society of London, 98, Vol. 98, No. 1089, 1982, pp. 199-209. doi:10.1098/rstb.1982.0082

[51] H. A. Simon, "The Functional Equivalence of Problem Solving Skills,” Cognitive Psychology, Vol. 7, No. 2, 1975, pp. 268-288. doi:10.1016/0010-0285(75)90012-2

[52] V. Goel and J. Grafman, "Are the Frontal Lobes Implicated in 'Planning' Functions? Interpreting data from the Tower of Hanoi,” Neuropsychologia, Vol. 33, No. 5, 1995, pp. 623-643. doi:10.1016/0028-3932(95)90866-P

[53] D. Wechsler, "Wechsler Adult Intelligence Scale Revised," Psychological Corporation, Cleveland, 1981.

[54] B. R. Aronowitz, E. Hollander and C. De Caria, "Neuropsychology of Obsessive-Compulsive Disorder," Neuropsychiatry, Neuropsychology and Behavioral Neurology, Vol. 7, No. 2, 1994, pp. 81-86.

[55] S. Rasmussen and J. L. Eisen, "Phenomenology of OCD: Clinical Subtypes Heterogeneity, and Coexistence,” In: J. Zohar, T. Insel and S Rasmussen, Eds., The Psychobiology of Obsessive-Compulsive Disorder, Springer, New York, 1991, pp. 13-43.

[56] D. Wechsler, "Wechsler Memory Scale,” Psychological Corporation, San Antonio, 1987.

[57] M. N. Barahani, S. Nasirian and B. Yazdi, "Wechsler Memory Scale (A Form)-Persian,” Tehran Psychiatric Institute, Tehran, 1981.

[58] B. M. Gu, J. Park, D. H. Kang, S. J. Lee, et al., "Neural Correlates of Cognitive Inflexibility during Task-Switching in Obsessive-Compulsive Disorder," Brain, Vol. 131, No. 1, 2008, pp. 155-164. doi:10.1093/brain/awm277

[59] D. W. Evans, M. D. Lewis and E. Iobst, "The Role of the Orbito-Frontal Cortex in Normally Developing Compulsive-Like Behaviors and Obsessive-Compulsive Disorder,” Brain and Cognition, Vol. 55, No. 1, 2004, pp. 220234. doi:10.1016/S0278-2626(03)00274-4

[60] H. A. Berlin, E. T. Rolls and U. Kischka, "Impulsivity, Time Perception, Emotion and Reinforcement in Patients with Orbito-Frontal Cortex Lesions,” Brain, Electronic Publication Ahead of Print, 2004.

[61] S. Galderisi, A. Mucci, F. Catapano, A. C. Damato and M. Maj, "Neuropsychological Slowness in Obsessive-Compulsive Patients: Is It Confined to Tests Involving the fronto-Subcortical Systems?” The British Journal of Psychiatry, Vol. 167, 1995, pp. 394-398. doi:10.1192/bjp.167.3.394

[62] D. Head, D. Bolton and N. Hymas, "Deficits in Cognitive Shifting Ability in Patients with Obsessive Compulsive Disorder," Biological Psychiatry, Vol. 25, No. 7, 1989, pp. 929-937. doi:10.1016/0006-3223(89)90272-2

[63] A. Okasha, M. Rafaat, N. Mahallawy, G. El Nahas, A. Seif El Dawla, M. Sayed and S. El Kholi, "Cognitive Dysfunction in Obsessive-Compulsive Disorder," Acta Psychiatria Scandinavia, Vol. 101, No. 4, 2000, pp. 281-285.

[64] S. Saxena, A. Brody, K. M. Maidment, J. J. Dunkin, M. Colgan, S. Aborzian, M. E. Phelphs and L.R. Baxter, "Localized Orbitofrontal and Subcortical Metabolic Changes and Predictors of Response to Paroxetine Treatment in Obsessive-Compulsive Disorder,” Neuropsychopharmacology, Vol. 21, No. 6, 1999, pp. 683-693. doi:10.1016/S0893-133X(99)00082-2 
[65] B. Milner, "Effects of Different Brain Lesion on Card Sorting: The Role of Frontal Lobes," Archives of Neurology, Vol. 9, No. 1, 1963, pp. 90-100. doi:10.1001/archneur.1963.00460070100010

[66] J. D. Henry, “A Meta-Analytic Review of Wisconsin Card Sorting Test and Verbal Fluency Performance in Obsessive-Compulsive Disorder," Cognitive Neuropsychiatry, Vol. 11, No. 2, 2006, pp. 156-176. doi:10.1080/13546800444000227

[67] R. Purcell, P. Maruff, M. Kyrios and C. H. Pantelis, "Neuropsychological Deficits in Obsessive-Compulsive Disorder: A Comparison with Unipolar Depression, Panic Disorder and Normal Controls," Archives of General Psychiatry, Vol. 55, No. 5, 1998, pp. 415-423. doi:10.1001/archpsyc.55.5.415

[68] C. Härting and H. J. Markowitsch, "Neuropsychologische Befunde der Zwangsstörung,” Fortschritte der Neurologie und Psychiatrie, Vol. 65, 1997, pp. 509-515.

[69] A. K. Kuelz, F. Hohagen and U. Voderholzer, "Neuropsychological Performance in Obsessive-Compulsive Disorder: A Critical Review,” Biological Psychology, Vol. 65, No. 3, 2004, pp. 185-236. doi:10.1016/j.biopsycho.2003.07.007

[70] M. Jenike, “Theories of Etiology,” In: M. A. Jenike, L. Baer and W. E. Minichiello, Eds., Obsessive-Compulsive Disorder: Theory and Management, PSQ Inc., Litteton, 1986.

[71] D. J. Stein, "Advances in the Neurobiology of Obsessive Compulsive Disorder," Psychiatric Clinics of North America, Vol. 23, No. 3, 2000, pp. 545-562. doi:10.1016/S0193-953X(05)70180-5

[72] S. Moritz, M. Kloss, H. Jahn, M. Schick and I. Hand, "Im- pact of Comorbid Depressive Symptoms on Nonverbal Memory and visuospatial Performance in ObsessiveCompulsive Disorder,” Cognitive Neuropsychiatry, Vol. 8, No. 4, 2002, pp. 261-272. doi:10.1080/135468000344000020

[73] S. Wilhem, R. J. McNally, L. Baer and I. Florin, “Autobiographical Memory in Obsessive-Compulsive Disorder,” British Journal of Clinical Psychology, Vol. 36, No. 1, 1997, pp. 21-31. doi:10.1111/j.2044-8260.1997.tb01227.x

[74] I. H. Gotlib, J. E. Roberts and I. E. Gilboa, "Cognitive Interference in Depression,” In: I. G., Sarason, Ed., Cognitive Interference: Theories, Methods, and Findings, Hillsdale, Erlbaum 1996, pp. 347-377.

[75] S. Moritz, M. Kloss, H. Hahn, M. Schick and I. Hand, "Impact of Comorbid Depressive Symptoms on Nonverbal Memory and Visuospatial Performance in ObsessiveCompulsive Disorder,” Cognitive Neuropsychiatry, Vol. 8, No. 4, 2003, pp. 261-272. doi:10.1080/135468000344000020

[76] S. Moritz, D. Jacobsen, m. Kloss, S. Fricke, M. Rufer, I. Hand, "Examination of Emotional Stroop Interference in Obsessive-Compulsive Disorder,” Behavioral Therapy, Vol. 42, No. 6, 2004, pp. 671-682. doi:10.1016/S0005-7967(03)00190-6

[77] J. R. Wendland, P. R. Moya, M. R. Kruse, et al., “A Novel, Putative Gain-of-Function Haplotype at $\mathrm{SLC}_{4} \mathrm{~A}_{4}$ Associates with Obsessive-Compulsive Disorder," Human Molecular Genetics, Vol. 17, No. 5, 2008, pp. 717-723. doi:10.1111/j.2044-8260.1997.tb01227.x

[78] I. M. Blackburn, “Coping with Depression,” Chambers, Endinburn, 1987. 